\title{
The Uniform Statistical Model of Fatigue Strength
}

\author{
Vladislav Turko, Institute of Aeronautics, Faculty of Transport and Mechanical Engineering, \\ Riga Technical University
}

\begin{abstract}
The uniform statistical model of fatigue strength is provided in the article. This model combines parameters of the probability distribution functions (PDF) of fatigue endurance limit and fatigue life time, $S-N$ curve and uses only four parameters. The offered model describes the area of multi-cycle fatigue, characteristic of a local zone of dependent accumulation of fatigue damage (the high level of survivability). For this local zone, the two-parametric doubleexponential probability distribution function with logarithmic fatigue life time (DEDF) is fair. By estimating fatigue strength parameters based on the results of tests, more than 600 specimens are given in the paper.
\end{abstract}

Keywords - Fatigue endurance limit, fatigue life time, fatigue strength parameters, probability distribution functions, $S-N$ curve.

\section{INTRODUCTION}

It is known that characteristics of fatigue strength consist of statistical descriptions of the fatigue endurance limits, fatigue life time and the S-N curve [1]. In the accepted practice, parameters of all three fatigue characteristics are determined by results of separate experiment test plans, independent of each other. Thus, the estimation of parameters of probability distribution functions of fatigue strength characteristics is carried out by the principle of the best interpolation of the data obtained in tests with the following subsequent extrapolation of results to the area of operational loading. However, such extrapolation is carried out ignoring the change in physical processes of accumulation of fatigue damage when the level loading of the object changes. Change of the mechanism of accumulation of fatigue leads to change of a type of PDF. However, it is impossible to check a kind of PDF for working conditions because of high cost and duration of such tests.

At best, the number of determined parameters is usually not less than six. Reduction in the number of determined parameters sharply reduces the number of demanded tests or increases the accuracy of parameter estimation for the same quantity of the tested objects [2].

In engineering practice related to the estimation of safe life time (the technical system resource) it is interesting to define areas of small values of distribution functions of cumulative probabilities (the "left tail") [3]. In studies [4] [6] it is shown that for the description of fatigue durability in operating conditions the greatest preference is given to a two-parametrical double-exponential probability distribution function with logarithmic fatigue life time. In the mathematical theory of reliability, this probability distribution function is known as the distribution of "maxima" [7]. The results of fatigue tests of specimens and objects of the high survivability show that the distribution function of "maxima" satisfactory describes also fatigue durability at a high level of loading.

As a result, the first premise of the statistical model is the mode of fatigue durability distribution function that has the following expression:

$$
F(N)=e^{-e^{\left(\frac{-\lg N-\alpha}{\beta}\right)}},
$$

where $N$ - number of load cycles, $\alpha$ - location parameter of the distribution function, $\beta$ - scale parameter of the distribution function.

Numerous studies show that S-N curves of fatigue have points of breaks of S-N curves, multimodality of the distribution density, non-monotonic change in some parameters (dispersion of fatigue durability, functions of intensity, etc.) [8] - [10].

It is possible to explain such effects by a change in the mechanism of fatigue damage accumulation due to a change in the loading level of the object. The observed brake of S-N curve is often followed by a change in the tilting angle of $\mathrm{S}-\mathrm{N}$ curve. For practical convenience, it is best to describe $\mathrm{S}-\mathrm{N}$ fatigue curve as a piecewise and linear approach [6], where the inclination of S-N fatigue curve (or exponent $m$ defined by an angle of linear piece) will depend on the level of loading of an object.

The second premise of the statistical model is the mode of S-N curve that has the following expression:

$$
\sigma_{i}^{m_{i}} N_{i}=\text { const }
$$

or

$$
m_{i} \lg \sigma_{i}+\lg N_{i}=\text { const }
$$

where $m_{i}$ - the tilting angle of S-N curve sectional-linear part numbered $i, \sigma_{i}$ - the loading level (stress, force, load etc.), $N_{i}$ - durability (number or loading cycles, life time, endurance etc).

The third premise of the given statistical model is the following range of its definition:

more than one million of loading cycles, exponent $m$ of S-N curve is more than six. 


\section{The UnIform StAtisticAl Model of the FAtiguE STRENGTH}

The present section will show how fatigue durability distribution function is linked with the limit of endurance probability distribution function, $\mathrm{S}-\mathrm{N}$ fatigue curve and "cut-off" sensibility cycle limit. If the probability distribution function of fatigue durability is known, for some assumptions of a kind of $\mathrm{S}-\mathrm{N}$ fatigue curve it is possible to receive an expression for PDF of a limit of endurance [1], [11]. Let us assume that in case of low load levels the PDF of fatigue durability belongs to the same PDF family, exactly to double-exponential PDF with logarithmic life time (1), where $\lg N=\tau$. Let us also assume that PDF location $a(\sigma)$ and scale $b(\sigma)$ parameters are changed versus load level $\sigma$ only.

$$
F(\tau \mid \sigma)=e^{-e^{\left(\frac{-\tau-a(\sigma)}{b(\sigma)}\right)}}
$$

Let us introduce:

$$
\varphi(\tau \mid \sigma)=\frac{-\tau-a(\sigma)}{b(\sigma)}
$$

Function (4) will have properties of PDF if the following conditions are satisfied:

$$
\begin{array}{llll}
\text { if } & \sigma \rightarrow 0 & \varphi(\tau, \sigma) \rightarrow-\infty & \text { or } F(\tau \mid \sigma) \rightarrow 0 \\
\text { if } & \sigma \rightarrow \infty & \varphi(\tau, \sigma) \rightarrow+\infty & \text { or } F(\tau \mid \sigma) \rightarrow 1,0
\end{array}
$$

It is easy to see that proportionality of (5) to logarithm $\sigma$ meets this condition. Let us designate $s=\lg \sigma$ and $\varphi(\tau \mid \sigma)$ $=s$.

It is known that in the domain of the model (the third premise) if the load is increased, the variance and the coefficient of variation decrease [12] - [15].

For PDF (4) the coefficient of variance $v(\tau, \sigma)$ is as follows:

$$
v(\tau, \sigma)=\frac{\sqrt{D\{\tau \mid \sigma\}}}{M\{\tau \mid \sigma\}}=\frac{\pi / \sqrt{\sigma}}{\frac{a(\sigma)}{b(\sigma)}+\text { Euler's const }^{\prime}}
$$

where:

$D\{\tau\}=\frac{\pi^{2}}{6} b(\sigma)^{2}-$ variance of life time $\tau$ under load $\sigma$;

$b(\sigma)$ - scale parameter of PDF (4);

$M\{\tau\}=a(\sigma)-b(\sigma) *$ Euler's $^{\prime}$ const - mathematical expectation of life time $\tau$;

$a(\sigma)$ - position parameter;

Euler's const $--0.5772 \ldots$

Then it is possible to assume:

$$
b(\sigma)=\frac{C}{s^{m}}
$$

$$
\frac{a(\sigma)}{b(\sigma)}=\gamma s^{m}+\theta
$$

Let us denote:

$$
\begin{aligned}
& \gamma C=\tau_{0} \\
& C[\theta-\text { Euler'sconst }]=P \\
& M\{\tau\}=\tau_{a v}
\end{aligned}
$$

The equation of S-N fatigue curve is obtained for average values of durability by substituting the expression of mathematical expectation in (6) and taking into account (8):

$$
\left(\tau_{a v}-\tau_{0}\right) s^{m}=P
$$

Fatigue S-N curve is received for quantile with the level of probability p by substituting (7) and (8) in (4) and twice taking the logarithm:

$$
\left(\tau_{p}-\tau_{0}\right) s^{m}=C[-f(p)+\theta],
$$

where $-f(p)=\ln (-\ln (p)$ and $p$ is quantile of the level of probability $\mathrm{p}$.

By denoting:

$$
\begin{aligned}
& A\{\tau\}=\frac{\theta C}{\tau-\tau_{0}} \\
& B\{\tau\}=\frac{C}{\tau-\tau_{0}}
\end{aligned}
$$

we receive

$$
F(s \mid \sigma)=e^{-e^{\left(\frac{-s^{m}-A\{\tau\}}{B\{\tau\}}\right)}}
$$

As a result, the PDF endurance limit on the accepted base also has a two-parametrical double - exponential probability distribution function with logarithmic fatigue life time.

To estimate the offered model parameters, it is necessary to address to the results of tests of more than 2000 of D16T alloy specimens [11].

\section{EXPERIMENTAL DATA}

Table I presents the experimental values of PDF parameters of fatigue life time.

TABLE I

The Results of Fatigue Tests of SPECimens

\begin{tabular}{|l|l|l|l|l|l|l|}
\hline $\begin{array}{l}\text { Stress } \\
\text { load } y, \\
\mathrm{~kg} / \mathrm{mm}^{2}\end{array}$ & $s=\lg y$ & $\begin{array}{l}\text { Mean life } \\
\text { time } \\
\phi=\lg N\end{array}$ & $\begin{array}{l}\text { Std. } \\
\text { Dev. } \\
\text { of } \phi\end{array}$ & $\begin{array}{l}\text { Coeff. } \\
\text { variance } \\
v(y)(6)\end{array}$ & $\begin{array}{l}\text { Scale } \\
\text { Param. } \\
b(y) \\
(7)\end{array}$ & $\begin{array}{l}a(y) / b(y) \\
(8)\end{array}$ \\
\hline 20 & 1.301 & 5.65 & 0.222 & 0.0393 & 0.1731 & 32.058 \\
\hline 18 & 1.255 & 6,18 & 0.290 & 0.0483 & 0.2261 & 25.977 \\
\hline 16.5 & 1.217 & 6,23 & 0.321 & 0.0515 & 0.2503 & 24.327 \\
\hline 15 & 1.176 & 6,52 & 0.307 & 0.0471 & 0.2394 & 26.653 \\
\hline 14 & 1.146 & 6,96 & 0.389 & 0.0559 & 0.3033 & 22.366 \\
\hline 13 & 1.114 & 7,33 & 0.419 & 0.0572 & 0.3267 & 21.845 \\
\hline
\end{tabular}


The primary experimental data of the specimen fatigue tests allow determining all parameters of the offered statistical model. Therefore, it is necessary to estimate the following model parameters:

$m, C$ determined by (7), and $\gamma, \theta$ determined by ( 8 ).

These four parameters contain all information about the fatigue strength: fatigue endurance limits, fatigue life time and S-N curve. Diagrammatically the S-N fatigue curve looks like a straight line in a graph with double logarithmical coordinates $s=\lg \sigma$ versus $\tau=\lg N$.

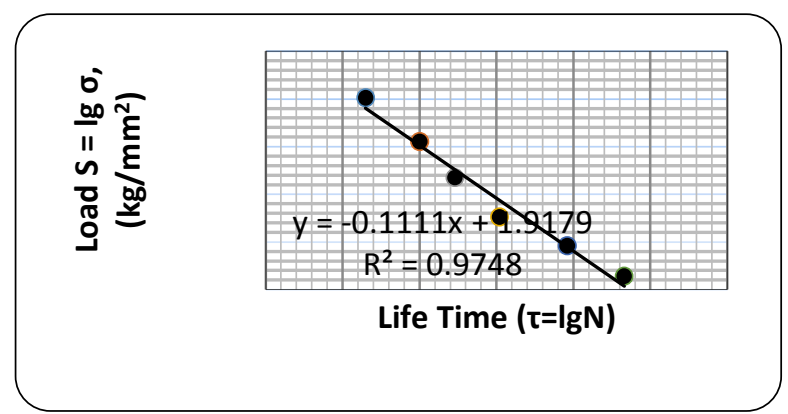

Fig. 1. S-N fatigue curve in a diagram with double logarithmical coordinates "load (stress) - life time (cycles)".

According to (7), the greater the load is, the smaller the parameter $b(s)$ is.

Figure 2 demonstrates a decrease in the scale parameter due to an increase in the stress level. Also, good straight line alignment is observed.

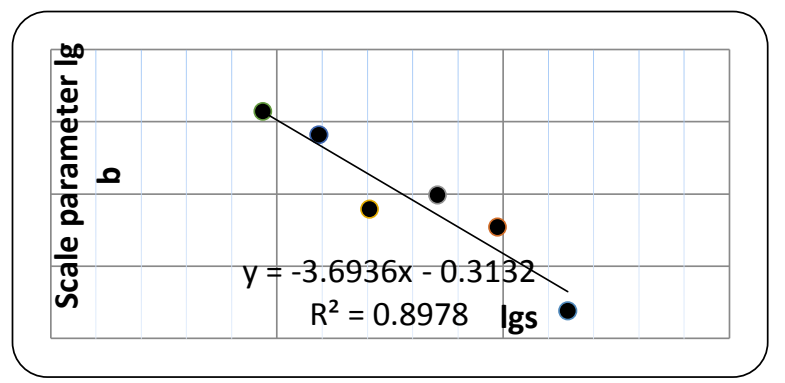

Fig. 2. A decrease in the value of scale parameter $b(s)$ due to an increase in stress $(\lg s=\lg \lg \sigma)$.

As shown in (6), the coefficient of variance has to decrease if the load increases, or the ratio of $a(s) / b(s)$ in (8) has also to increase. Indeed, as shown in Fig. 3 this dependence is near to linear.

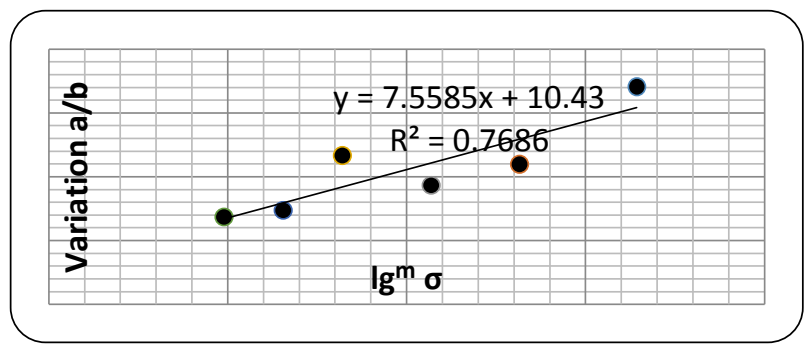

Fig. 3. An increase in the value of ratio of $a(s) / b(s)$ due to an increase in stress $\lg ^{m} \sigma$.

Parameters $C$ and $m$ of (7) are determined by experimental data (see Table I and Fig. 2). Thus, by taking the logarithm of the left and right side of (7) and applying a least square method, we receive:

$\lg b(s)=-0.313207-3.6936 \lg \cdot s$

or

$m=3.6936, \lg C=-0.313207, C=0.4862$

The same should be applied to (8):

$a(s) / b(s)=10.43+7.55847 \cdot s^{m}$

or

$\gamma \cdot=7.55847, \theta=10.43$

The adjustment of the received estimates of parameters with experimental data is shown in Fig. 2 and Fig. 3.

If we substitute the tested estimates of parameters in (9) and (10), we find:

$\tau_{0}=7.55847 \cdot 0.4862=3.675$

$P=(10.43+0.57742) \cdot 0.4862=5.352$

and also receive expression of $\mathrm{S}-\mathrm{N}$ fatigue curve for average values of durability:

$\left(\tau_{a v}-\tau_{0}\right) s^{m}=P$

S-N fatigue curve is received for quantile of the level of probability p by inserting (7) and (8) to (4) and twice taking the logarithm of both sides:

$\left(\tau_{p}-\tau_{0}\right) s^{m}=C[-f(p)+\theta]$

where $-f(p)=\ln (-\ln (p)$ and $p$ is fixed quantile of PDF.

Side by side we calculate (14) and (15):

$$
\begin{aligned}
& A\{\tau\}=\frac{10.43 \cdot 0.4862}{\tau-\tau_{0}}=\frac{5.072}{\tau-\tau_{0}} \\
& B\{\tau\}=\frac{0.4862}{\tau-\tau_{0}} \\
& \tau_{0}=3.675
\end{aligned}
$$

and when inserting it in (16) the PDF of endurance level is deduced:

$F(s \mid \sigma)=e^{-e^{\left(\frac{-l g^{m}(\sigma)-\frac{5.072}{\tau-\tau_{0}}}{\frac{0.4862}{\tau-\tau_{0}}}\right)},}$

where $\tau$ is the accepted base of test.

Note that the offered statistical model includes the "cycles cut-off" effect or the cycle sensitivity level for small values of probabilities as $\tau_{0}$ value (27). Thus, the "cycles cut-off" number is equal to $N_{0}=4731$ load cycles. 
The parameters of $A\{\tau\}$ and $B\{\tau\}$ for different test cycle bases are shown in Table II.

If we take both sides of (23), we get a new transformation of S-N fatigue curve (Fig. 4) as double logarithmic coordinates and with account of "cut-off" load cycles. It seems to be the better fitting prediction linear data with experimental data, compared to Fig. 1.

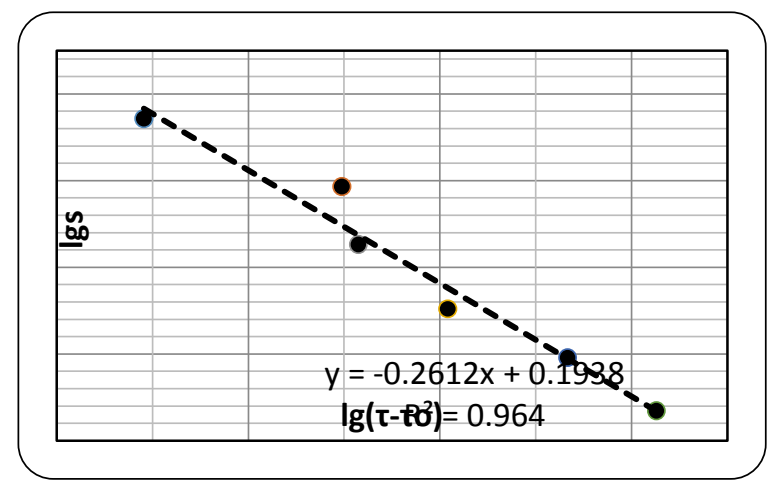

Fig. 4. The S-N fatigue curve for double logarithmic coordinates.

Now we consider the mode of endurance limit PDF for different test cycle bases.

TABLE II

THE PARAMETER OF PDF OF ENDURANCE LIMITS

\begin{tabular}{|c|c|c|c|}
\hline \multicolumn{2}{|c|}{ Test Base } & \multirow{2}{*}{$A(\phi)$} & \multirow{2}{*}{$B(\phi)$} \\
\cline { 1 - 2 }$N$ & $\phi=\log N$ & & \\
\hline $5 \cdot 10^{5}$ & 5.700 & 2.505 & 0.240 \\
\hline $1 \cdot 10^{6}$ & 6.000 & 2.182 & 2.209 \\
\hline $5 \cdot 10^{6}$ & 6.700 & 1.677 & 0.161 \\
\hline $1 \cdot 10^{7}$ & 7.000 & 1.525 & 0.146 \\
\hline $5 \cdot 10^{7}$ & 7.700 & 1.260 & 1.121 \\
\hline $1 \cdot 10^{8}$ & 8.000 & 1.173 & 0.112 \\
\hline
\end{tabular}

The PDF of endurance limits for test cycle bases is shown in Fig. 5 (test base $-1 \mathrm{ml}$ cycles), Fig. 6 (test base $10 \mathrm{ml}$ cycles) and in Fig. 7 (test base $-100 \mathrm{ml}$ cycles).

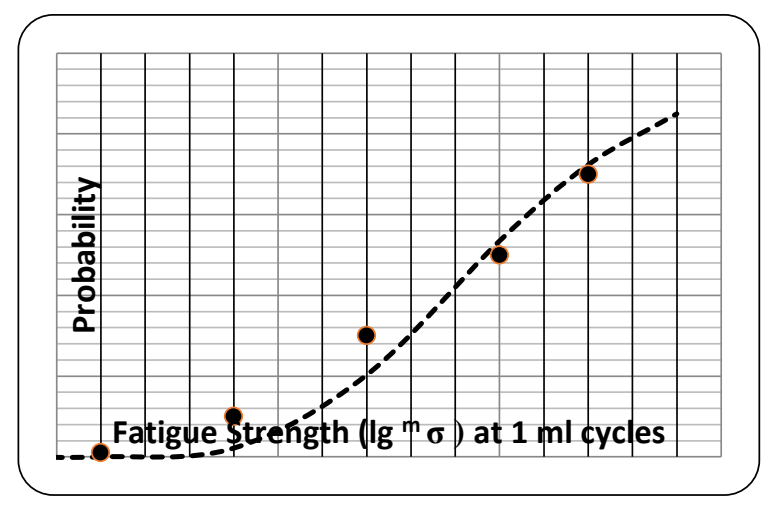

Fig. 5. The PDF of endurance limit for test base of $1 \mathrm{ml}$ cycles.

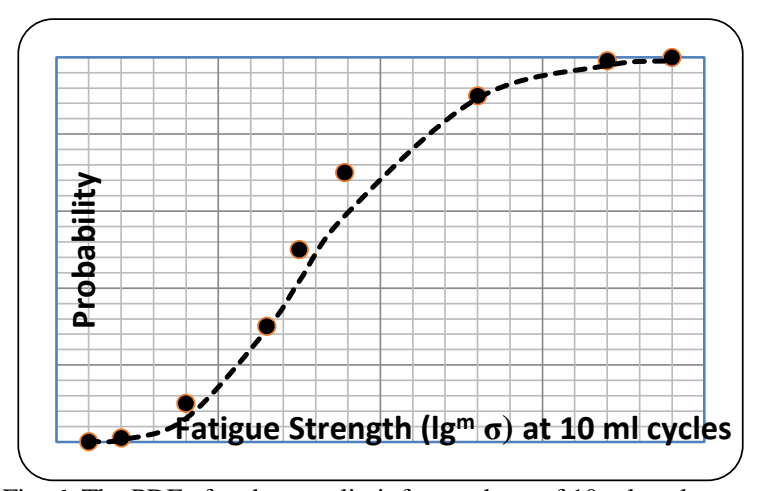

Fig. 6. The PDF of endurance limit for test base of $10 \mathrm{ml}$ cycles.

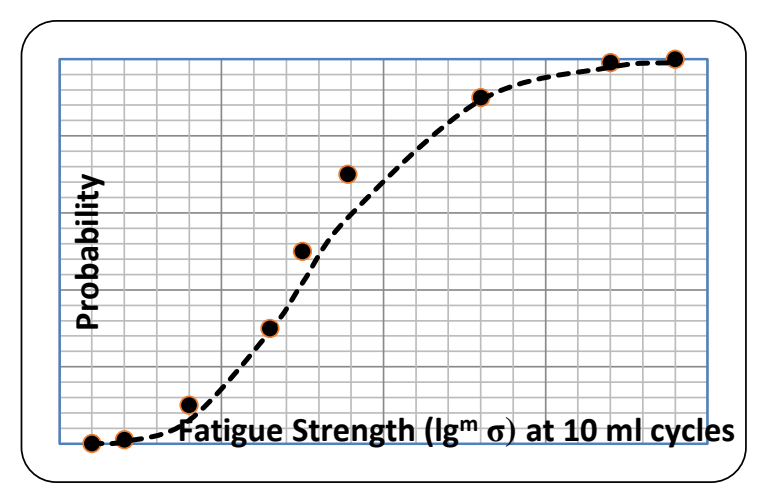

Fig. 7. The PDF of endurance limit for test base of $100 \mathrm{ml}$ cycles.

The analysis of the provided figures demonstrates that in the offered model the PDF of endurance limits presents satisfactory fitting to the experimental data when test cycle bases increase. The best data fitting is observed in the area of small probabilities, i.e., in the field of adoption of the engineering decision on durability of the studied object.

Thus, it is shown, that for a complete statistical description of characteristics of the fatigue strength (such as fatigue endurance limits, safe life durability, S-N fatigue curve, "cut-off" of cycles sensitivity) only four interconnected parameters are required, namely: $C-$ the parameter that determines a decrease in the variance (dispersion) of durability till failure, $m$ - the parameter of the inclination for logarithmic S-N fatigue curve, $\gamma$ and $\theta-$ parameters of the coefficient that determines a decrease in variation if the load is increased.

\section{CONCLUSiOnS}

The results of fatigue tests have proven that the offered model minimizes costs of the estimation of fatigue strength parameters. It allows estimating all main PDF parameters of fatigue strength characteristics based on a small number of the tested samples. It is especially important for research on the durability of large full-size technical design, tests of which are labour-consuming and expensive. It is necessary to emphasize that the range of definition of the obtained functions lies in the area of great values of safe life durability, high survivability of object of tests or low levels of loading. It is characteristic of operating conditions. The 
test reproduction of these conditions is difficult and often cannot be achieved experimentally. The offered [4] model based on phenomenological reasonable PDF of "maxima" two-parametrical double-exponential probability distribution function with logarithmic fatigue life time is suitable for the description of composite material specimens in order to correctly extrapolate the results of experiment.

\section{ACKNOWLEDGEMENTS}

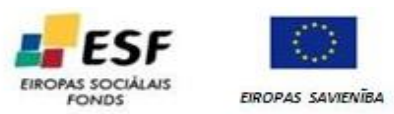

The research has been supported by the European Social Fund within the framework of project "Support for the Implementation of Doctoral Studies at Riga Technical University".

\section{REFERENCES}

[1] H. Kordonskij and J. Fridman. "Nekotorye voprosy verojatnostnogo opisania ustalostnoj dolgovecnosti”, Zavodskaa laboratoria, vol.42, pp. 829-847, 1976.

[2] H. Cramer, Matematiceskie metody statistiki. Moskva: Mir, 1975.

[3] M. Mil, A. Nekrasov, A. Braverman, L. Grodko, and M.Lejkand Vertolety. Rascet i proektirovanie. Cast.2 Kolebanija i dinamiceskaja prochnost. Moskva: Masinostroenie, 1967.

[4] V. Turko, "Model ustalostnogo razrušenija pri nizkih urovnjah nagruženija", presented at International Symposium on materials and design parts strength under sonic and ultrasonic frequency loading, Kiev, USSR, 1984.

[5] V. Turko, "Koefficient zapasa po ciklam pri nizkih urovnjah nagruzenija", presented at International conference on materials and design parts strength under sonic and ultrasonic frequency loading, Kiev, Ukraine, 1992.

[6] V. Turko, "Estimation of Fatigue Durability Dispersion in Operation by Results of Tests and Loading Measurements", Transport and Engineering. The Scientific Journal of Riga Technical University, vol. 34, part 6, pp. 17-22, 2010
[7] B. Gnedenko, J. Belaev, and A. Solovev, "Matematiceskije metody v teorii nadeznosti”, Moskva: Nauka, 1965.

[8] V. Sabalin, "About the discontinuity of S-N curve for duralumin samples," Doklady AN SSSR, vol. 122, no. 4, pp. 600-602, 1958.

[9] L. Morozov, "Fatigue strength and safe life forecasting", presented at $2^{\text {nd }}$ All-Soviet Union Congress on mechanism units and machines theory, Odessa, USSR, 1984

[10] A. Sanavskij, "Modelirovanie ustalostnogo razrušenija v metallah. Sinergetika v aviacii". Monografija, Moskva, 2007

[11] M. Stepnov and E. Giacintov, Ustalost legkih konstrukcionnyh splavov, Moskva: Masinostroenie, 1973.

[12] A. Freudenthal, "Statisticeskij podhod $k$ hrupkomu razruseniû" Razrusenie. vol. 2, pp. 616-645, Moskva, 1975

[13] F. Bastener N., Bastien and J. Pome, "Statističeskij analiz novyh ustalostnyh ispytanij," in Ustalost $i$ vynoslivost metallov, Moskva: Izdatelstvo inostrannoj literatury, 1963, pp. 390-406.

[14] A. Selihov, "Obsaa model rasseania ustalostnoj pri regularnom nagruzenii," Naucnye zapiski CAGI, vol. XV, no. 2, pp. 57-71, 1984.

[15] V. Rajher, Razbros ustalostnoj dolgovecnosti. Moskva: LATMES, 2003.

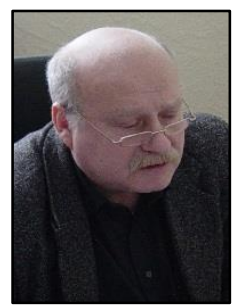

Vladislav Turko received a Doctoral Degree from the Aviation Institute, Riga Technical University in 2013. 1979 - 1982 - Postgraduate studies, Faculty of Aircraft Repair and Technology, Riga Institute of Civil Aviation Engineers named Lenin Komsomol. 1968 - 1974 - Mechanical Engineer of Aircraft and Engine Maintenance, Riga Institute of Civil Aviation Engineers named Lenin Komsomol.

Work experience: since 2013 - Deputy Director (scientific issues). 2009 - 2013 - Deputy Director

(ISO quality system). 1997 - 2009 - Technical Director, Riga scientific and experimental centre "Aviatest LNK" Ltd. 1992 - 1997 - Senior Scientist at RSEC "Aviatest LNK" Ltd., Scientist at Riga branch GosNII GA.

His fields of research: material fatigue, fatigue cracks, acoustic emission, ultimate loads and strain, fatigue mathematical models.

Address: Institute of Aeronautics, Faculty of Transport and Mechanical Engineering, Riga Technical University, Lomonosova 1A, k-1, Riga, LV1019, Latvia.

Phone: +37167089990

E-mail: Vladislav.Turko@ rtu.lv 